\title{
Sindicalismo y trabajo: la experiencia de los jóvenes bogotanos desde sus repertorios interpretativos*
}

\author{
Unionism and Work. The experience of young people \\ in Bogota since its interpretative repertories
}

Recibido: 28 de octubre de 2014 | Aceptado: 11 de septiembre de 2015

\author{
OSCAR ANDRÉS LÓPEZ CORTÉS ** \\ LILIANA VARGAS MONROY \\ Carolina Covelli Reyes \\ María Angélica Pérez Aldana \\ Pontificia Universidad Javeriana, Bogotá, Colombia
}

Laura Patricia Santamaría Martínez

doi: 10.11144/Javeriana.upsy14-5.stej

Para citar este artículo: López, O. A., Vargas, L., Covelli, C., Pérez, M. A., \& Santamaría, L. P. (2015). Sindicalismo y trabajo: la experiencia de los jóvenes bogotanos desde sus repertorios interpretativos. Universitas Psychologica, 14(5), 1795-1808. http://dx.doi.org/10.11144/Javeriana.upsy14-5.hcva

Artículo de investigación. Producto de la práctica investigativa: "Mundo del trabajo, culturas y subjetividades", de la Facultad de Psicología de la PUJ, adelantada durante el 2013 en convenio con la CGT. Sin financiación externa.

** Correos electrónicos: andreslopezc@yahoo.com; liliana.vargas@javeriana.edu.co; mapa0326@ hotmail.com; lapasama_09@hotmail.com; caro. covelli@gmail.com
RESUMEN

Este artículo examina algunos de los significados otorgados por los jóvenes bogotanos al sindicalismo y al trabajo. Se realizaron nueve entrevistas etnográficas a igual número de jóvenes, provocando la narración de su vida como trabajadores y/o como trabajadores-sindicalizados. Como marco al proceso de indagación, se revisó bibliografía relacionada con los siguientes problemas: la construcción social de la categoría “joven” y su delimitación conceptual; las transformaciones contemporáneas del mundo del trabajo y su relación con las condiciones sociolaborales que enfrentan los jóvenes actualmente, explorando aspectos del surgimiento del movimiento obrero en Colombia y su estado actual en comparación con otros países de la región. Se abordó la pregunta de investigación: icuáles son los significados asociados al trabajo y al sindicalismo, construidos por jóvenes trabajadores habitantes de Bogotá?, examinando las entrevistas a partir de la propuesta de análisis de discurso de los psicólogos sociales Jonathan Potter y Margaret Wheterell (1996), basada en la identificación de repertorios interpretativos. Finalmente, se discutieron los resultados encontrados, señalando la tensión emergente entre dos perspectivas narrativas de los jóvenes trabajadores, según tengan o no relación con el movimiento sindical.

Palabras clave

jóvenes y trabajo; jóvenes y sindicalismo; análisis de discurso; repertorios interpretativos

\section{A B S T R A C T}

This article aims to examine the meanings that, nowadays, young people give to work and unionism. Nine ethnographic interviews with young workers were conducted about their working life as unionized and non-unionized workers. The conceptual framed was composed by a review of the literature related to the following topics: the social construction of young people, the contemporary transformation of work and the history of unionism in Colombia. The research question was addressed by identifying the participant's interpretative repertories (Potter y Wheterell, 1996). The results show a tension between the repertoires used by young workers according to their position as union or non-union members.

Keywords

young people and work; young people unionized; discourse analysis; interpretative repertories 


\section{La juventud como concepto histórico}

El concepto de juventud, como marcador etario, emerge en Europa entre los siglos XVIII y XIX (Reguillo, 2000 en Dávila León, 2002). Las condiciones de trabajo y la necesidad de regular el acceso de la población al mundo laboral, el establecimiento de un periodo de educación obligatorio previo al trabajo, la creación de ejércitos nacionales a través del servicio militar y la regulación del derecho de voto figuran entre las causas que propiciaron dicha emergencia (Margulis \& Urresti, 1996). Pese a las diversas definiciones, estas coinciden en que la "juventud" remite a una etapa de transición entre la dependencia infantil y la autonomía adulta, determinada por las consideraciones sociales mantenidas sobre ella; concepto que alude a una "norma construida históricamente, desarrollada socialmente e interiorizada psicológicamente" (Souto, 2007). En este sentido, la juventud entendida como grupo definido no es universal; su desarrollo, forma, contenido y duración obedecen a construcciones socioculturales dependientes del contexto; su conceptualización exige un encuadre histórico que dé cuenta de los cambios producidos por el surgimiento de las relaciones capitalistas (Morch, 1996 citado en Dávila León, 2002).

La juventud, como concepto histórico, es provocado por relaciones de poder, construido a partir de decisiones políticas e ideológicas y permite identificar un grupo social como "apto" para el trabajo. Alrededor de esta noción, se definen instituciones (centros de enseñanza, correccionales, reformatorios), normas (legales y sociales que definen quién es joven, cómo se debe comportar, el espacio que debe ocupar, las actividades permitidas), sistemas educativos (destinados a formar trabajadores productivos, dóciles y disciplinados) y surgen áreas de conocimiento (psicología evolutiva y de la juventud, criminalidad y violencia juvenil), entre otras tecnologías, encaminadas a incorporar al trabajo a un grupo poblacional cuya participación permite extraer la mayor rentabilidad posible.

Los límites temporales de la categoría "juventud" varían según aspectos relacionados con el desarrollo social, la legislación, las posibilidades de independencia económicopolítica y las percepciones sociales (Souto, 2007). Conforme a la Ley 1622 de 2013, en Colombia se clasifica como joven a la persona entre 14 y 28 años de edad. Las diferencias inciden en las oportunidades y condiciones laborales de la población joven, aspecto central del presente trabajo.

Existen múltiples estudios sobre la categoría juventud, desde quienes consideran tal expresión como una mera palabra que arbitrariamente asigna límites para ubicar a los sujetos en un determinado lugar (Bourdieu, 2002) hasta quienes resaltan la ambigüedad sociopolítica atribuida a la categoría, dado que se emplea para asignar a ese grupo etario la responsabilidad de ser "solución" y simultáneamente -según la intención del discurso- se le rotula como "generación perdida" (Palomino, 2002). Particularmente, interesan las investigaciones a propósito de la relación entre jóvenes y trabajo. Al respecto, abundante producción en las ciencias sociales ha observado las condiciones de trabajo y los significados que del mismo construyen los jóvenes trabajadores de hipermercados en Argentina (Abal, 2004, 2007, 2011; Guiamet, 2012, 2014; Longo, 2012), estudios que han empleado herramientas como la observación etnográfica y las entrevistas a profundidad. Otros estudios semejantes han sido adelantados en la industria automotriz (Battistini \& Wilkis, 2005) y la metalurgia (Svampa, 2009), en profesionales de la psicología (Orejuela, Bermúdez, Urrea, \& Delgado, 2013) e incluso, en el emprendimiento juvenil (Gámez, 2011). Pese a las grandes diferencias metodológicas y conceptuales existentes entre estos trabajos, una constante aparece en la mayoría: la relación entre neoliberalismo, flexibilización laboral, precarización del trabajo juvenil y debilitamiento de los sindicatos. Esta relación es fundamental para la presente investigación, lo que convoca a discutir algunos de esos textos en los siguientes apartados.

\section{Los paisajes posfordistas del trabajo para los jóvenes}

Con el fordismo, la racionalización de los procesos productivos, la producción en serie y la organización 
jerárquica e inflexible dieron lugar a relaciones de trabajo-empleo estables (Caamaño Rojo, 2005). Luego de la II Guerra Mundial, la diversificación de la producción y la inserción de la informática, fragmentaron el modelo de relaciones laborales y propiciaron nuevas formas de gestión del trabajo (Caamaño Rojo, 2005). Las nuevas tecnologías provocaron la deslocalización de los trabajadores (Huws, 2003), la exigencia de habilidades y competencias laborales "integrales" y la combinación de destrezas emocionales y comunicativas (Landa \& Merengo, 2010). Para reducir costos, los procesos productivos se fragmentaron mediante la tercerización (De la Garza, 2003), el empleo temporal devino condición habitual y la adaptación a la inestabilidad comenzó a valorarse como "ventaja" en la trayectoria profesional (Sennett, 2000). Así, disminuyeron las relaciones laborales estables y los vínculos entre las personas y sus lugares de trabajo. Los sistemas de remuneración priorizaron la rentabilidad de la empresa sobre el tiempo laborado, eliminaron los ingresos fijos y sometieron al trabajador a la contingencia y la inequidad, aumentando la productividad y socializando las pérdidas.

El aumento de reestructuraciones empresariales flexibilizó la producción y la organización del trabajo como respuesta a las exigencias de la competencia y las tendencias de consumo promovidas por los mercados internacionales (Caamaño Rojo, 2005). Los procesos de integración económica y la transnacionalización de la producción exigieron trabajadores móviles y generaron cambios en la percepción que estos tienen de sí mismos y de su trabajo, provocando el aumento de la intervención empresarial en la gestión y el desarrollo de las tareas, el tiempo de labor y la individualización del sujeto. Estas transformaciones replantean la noción y formas del trabajo, y suscitan para los jóvenes la emergencia de "nuevos trabajos" caracterizados por su heterogeneidad, precariedad, temporalidad e intensificación (Frassa, 2007).

En tal panorama, las condiciones sociolaborales de los jóvenes se dificultan a lo largo del ciclo: al inicio, enfrentan mayores obstáculos para conseguir empleo; al obtenerlo, padecen condiciones inseguras e inestables y aumenta la presión ejercida por la alta competitividad y la creciente demanda de calificación; durante la relación laboral, usualmente devengan salarios más bajos, algunos incluso no devengan -como los aprendices- a cambio de "auxilios de sostenimiento"; sus vínculos laborales, generalmente tercerizados, son inestables y les impiden sindicalizarse. Por último, los jóvenes afrontan largos periodos de desempleo, lo cual les dificulta completar ciclos de formación, cualificarse académicamente y postularse a mejores empleos (Orejuela et al., 2013).

La educación es un factor importante en la inserción laboral, al acceso a trayectorias ocupacionales exitosas, mejores empleos y una vida digna, libre de privaciones severas e incertidumbres laborales (De Oliveira \& Mora Salas, 2012). No obstante, los cambios descritos han truncado tales expectativas para muchos; las actuales condiciones del mercado no compensan las inversiones hechas en educación y distribuyen injustamente las oportunidades laborales y de desarrollo profesional. Para estos autores, algunos jóvenes integran una élite de la fuerza laboral hipercualificada y con altas expectativas de desarrollo profesional, pero enfrentan economías en reestructuración incapaces de generar su[cientes puestos de trabajo. En este contexto, un alto nivel educativo es condición necesaria más no su $\square$ ciente para insertarse laboralmente y ejercer exitosamente la profesión. Peor situación afrontan los jóvenes con baja escolaridad, quienes acceden a los peores empleos, con menor remuneración y en sectores de baja productividad (Weller, 2008). Esto explica parcialmente los elevados índices de desempleo y subempleo de los jóvenes, grupo que concentra a quienes buscan trabajo por primera vez, afrontan mayor dificultad para encontrarlo y, cuando lo ubican, tienden a permanecer menos tiempo.

Las condiciones descritas impiden la libertad sindical entre los jóvenes. Si a esto se agregan actos antidemocráticos de algunos sindicatos, la distancia y el recelo tienden a aumentar. Como argumenta Abal (2011), la estricta jerarquía sindical, las formas de organización autoritarias y con fuerte concentración de poder entre sus cúpulas, la coartación del disenso y la heterogeneidad, entre otros aspectos, impiden que el vínculo sindical sea un referente de 
subjetividad laboral para los jóvenes. Si bien estas condiciones son registradas por la autora luego del estudio del caso de los hipermercados en Argentina, algunos de estos comportamientos son comunes en otros países. Se pasará, entonces, a la revisión de algunos de los matices particulares del sindicalismo, en la zona andina suramericana.

\section{Sindicalismo en la región Andina}

La libertad sindical es una de las más afectadas por las condiciones descritas. Durante la última década del siglo XX, varios países latinoamericanos disminuyeron los derechos en el trabajo, so pretexto de que flexibilizar y externalizar las relaciones laborales es inevitable para reestructurar el aparato productivo y enfrentar los retos de la globalización (Sánchez-Castañeda, Reynoso, \& Palli, 2011). Por ejemplo, mediante la Ley de Fomento del Empleo, en Perú se eliminaron los beneficios laborales y el acceso a la seguridad social para los jóvenes vinculados por contrato de aprendizaje y se aupó la celebración de contratos temporales. En Argentina, los gobiernos neoliberales continuaron el trabajo de la dictadura al impulsar la flexibilización, lo que afectó la posibilidad de sindicalización de los más jóvenes (Abal, 2004; Longo, 2011). Si bien países como Argentina subrogaron algunas reformas de los noventa, en lo sustancial el modelo ha conservado su esencia (Longo, 2012).

En 1991, Chile aprobó leyes orientadas por tres principios: concertación social, equidad con autonomía social y mayor fiscalización al cumplimiento de la legislación laboral (Hernández, 2006), contribuyendo a superar la herencia dejada por la dictadura. No obstante, actualmente Chile presenta unas condiciones de elevada inequidad y profunda segmentación en la inserción laboral (Soto \& Gaete, 2013). En Ecuador, por mandato constitucional, desde el 2008 se prohíbe la intermediación laboral y cualquier forma de precarización de las relaciones de trabajo (Ermida \& Colotuzzo, 2009), lo que ha generado una mejora de las condiciones laborales en ese país.

La flexibilización laboral en la región ha implicado reformas legislativas diversas, pero con rasgos comunes, en particular, los relativos a la proliferación de formas de vinculación temporal, subcontratación o tercerización, debilitamiento de la negociación colectiva y el derecho de huelga. Estos cambios, sumados a lo que Abal denomina carencia de "experiencias propias de relación con la instancia sindical" hacen que para los jóvenes el sindicalismo no sea más que un "nombre vacío de contenido y significado" (Abal, 2007, p. 706). Algunas de las entrevistas recaudadas en el marco de la presente investigación, coinciden con lo señalado por la autora argentina, en particular en aquellos casos en los cuales los jóvenes trabajadores carecen de contacto con el movimiento sindical.

Aunque es difícil determinar si las características de la flexibilización descritas son consecuencias o, por el contrario, causas de las formas de subjetividad emergentes entre los jóvenes, parece haber relación evidente entre el contexto de estas transformaciones laborales y lo que Abal (2007) señala como la carencia identitaria de los trabajadores jóvenes. Al respecto, según la autora muchas empresas buscan trabajadores desprovistos de identidad, para poder dotarlos de una acorde a los intereses corporativos; mediante tal acción, se espera que el joven no impugne las relaciones laborales como asimétricas y de fuerza, ni logre configurar la relación capital-trabajo como una de tipo antagónico. Igualmente, el modo de subjetivación que apela a sofocar y reprimir las prácticas de resistencia es más eficaz en las empresas que contratan trabajadores jóvenes, dada la carencia entre ellos de "determinados saberes políticos que cuestionen un orden social" (p. 721).

Coincidimos parcialmente con Abal, en tanto parte de la estrategia empresarial parece encaminada a dotar de cierta subjetividad a los trabajadores de forma que sea más sencillo ejercer control sobre ellos, lo cual además no es una novedad, la diferencia estaría en las técnicas empleadas. Pero disentimos de la afirmación sobre la carencia de identidad en los jóvenes. Que los referentes de construcción identitaria no sean los mismos no se sigue que los trabajadores jóvenes carezcan de identidad; simplemente, la construyen a través de otros espacios de socialización, dentro de los cuales el trabajo no 
tiene la misma centralidad que para otros grupos etarios, y así, el trabajo adquiere significado únicamente como mecanismo de obtención de recursos necesarios para el despliegue de otras formas de relacionamiento. Como plantea Dubar (2005), la flexibilización laboral puede generar que el trabajo sea solamente un elemento más de la constitución identitaria del sujeto, quien, ante la ausencia de reconocimiento en sus espacios laborales, tiende a construir su identidad en escenarios diferentes del trabajo.

Adicionalmente, cabe preguntarse cuáles serían esos "determinados saberes políticos" capaces de cuestionar el orden social. No creemos que exista un único saber político capaz de semejante tarea. Por el contrario, las erupciones de los movimientos sociales liderados por jóvenes en Latinoamérica han mostrado que luchas políticas por el territorio, la identidad, la recuperación de los saberes ancestrales, el cultivo de las semillas nativas en pos de la autonomía alimentaria, la libre circulación del conocimiento a través de movimientos como el creative commons, entre muchos otros, se erigen como espacios políticos que no solo cuestionan el orden social, sino que incluso pueden llegar a subvertirlo. Así como, lamentablemente, muchos jóvenes pertenecientes a partidos políticos y a organizaciones sindicales contribuyen a mantener el statu quo.

También cabe señalar que muchos de los movimientos reivindicativos y progresistas de América Latina surgen como una alternativa ante las extremas condiciones de precarización, exclusión, desempleo, pobreza y ausencia del Estado, afrontados en el sur global. No parece entonces existir una regla mediante la cual se pueda generalizar acerca de los efectos que produce entre los jóvenes trabajadores pertenecer o no a un sindicato. Como plantea Julieta Longo a propósito de la afirmación de Paugman (citado en Longo, 2012), según la cual el aumento de la precariedad en el trabajo provoca reacciones radicales pero despolitizadas, apatía política y ausencia de organización, no se puede establecer "una relación mecánica entre la precariedad y las formas que asumen las resistencias de los trabajadores" (Longo, 2012, p. 391). Razón le asiste a Longo, especialmente si se tiene en cuenta que la autora realizó su análisis precisamente a partir de entrevistas realizadas a jóvenes trabajadores de hipermercados en la ciudad de La Plata (Argentina).

Como veremos adelante, múltiples y contradictorios significados del trabajo emergen en los discursos de los jóvenes trabajadores en Bogotá, no como resultados de una simple falta de coherencia, sino como la expresión de la complejidad y la diversidad que reviste la constitución de la subjetividad. En este sentido, se trata de una configuración más próxima a la idea de la heterogeneidad (De la Garza, $2003,2011)$ que caracteriza a las formas contemporáneas del trabajo, antes que a la de pérdida o ausencia de identidad entre los trabajadores jóvenes. Insistimos en la necesidad de contextualizar los estudios al respecto, comenzando por una reconstrucción histórica de las condiciones de emergencia de prácticas y discursos, como se intenta hacer en el siguiente apartado.

\section{Sindicalismo en Colombia}

Como parte del análisis documental adelantado en esta investigación, fueron revisadas, además de la colombiana, las legislaciones laborales vigentes en México, Argentina, Perú, Uruguay, Ecuador, Chile y Venezuela, en torno a: vinculación laboral temporal, subcontratación o tercerización laboral, negociación colectiva y derecho de huelga. La información encontrada muestra que, de los ocho países comparados, la legislación colombiana es una de las más restrictivas de la libertad sindical. Al permitirle al empleador terminar el contrato aunque la necesidad del servicio persista, así como subcontratar a través de empresas de servicios temporales y figuras legales análogas, en la práctica la legislación colombiana impide al trabajador sindicalizarse por temor a perder el empleo. Otro tanto ocurre frente al derecho de huelga y negociación colectiva, ya que el Estado goza de amplias facultades para definir una actividad como servicio público esencial, prohibiendo así el derecho de huelga, como se lo ha hecho notar al Gobierno nacional el Comité de Libertad Sindical de la Organización Internacional del Trabajo ([OIT], 2006). Finalmente, mediante pactos colectivos, los empleadores en Colombia 
consiguen debilitar a las organizaciones sindicales al impedir a los trabajadores gozar de los beneficios convencionales.

El reconocimiento de los sindicatos en Colombia está marcado por una tendencia a la vulneración de las libertades civiles y políticas (Rosado Duque, 2005). A principios del siglo XX el país comenzó a crecer económicamente, incentivando la acumulación de capital, las exportaciones y el proceso de industrialización; al tiempo, emergieron pequeños sectores obreros de corrientes ideológicas distintas a las del cono sur (Urrutia, 1978). La palabra "sindicato" aparece por primera vez en la Ley 83 de 1931, luego de que el sindicalismo afrontara una etapa de estigmatización durante la década del 20 y de masacres como la ocurrida en las bananeras del Magdalena. Recuperada la hegemonía política del partido liberal, la cual se prolongó hasta mediados de los años 40, Colombia experimentó la expansión del sindicalismo (Rosado Duque, 2005). Dos centrales dominaban el panorama sindical: la CTC, de filiación liberal, y la UTC del conservatismo (Ostau de Lafont, 2012). Según el partido político en la Presidencia de la República, se garantizaba la acción a una u otra central, y estas funcionaban como extensiones de los ministerios de trabajo de turno. La década finalizaba con la promulgación en la OIT de los Convenios 87 y 98 sobre libertad sindical. Pasados los años cincuenta, caracterizados por dictaduras militares, violencia partidista y el inicio del conflicto armado, llegaría el sindicalismo independiente con la creación de la CUT, FECODE y la CGT, centrales que luego experimentaron un retroceso a causa del neoliberalismo y la expansión de la cultura y la violencia antisindical durante los noventa.

A través de las empresas de servicios temporales (en adelante EST) y otras figuras semejantes, Colombia adoptó el neoliberalismo desde la década del noventa, el cual ha profundizado mediante reformas como la adoptada por la Ley 789 de 2002. Respecto de las EST, la OIT sostiene que, junto a la contratación temporal, de formación o aprendizaje, en zonas francas, esta forma de tercerización afecta la libertad sindical de los jóvenes. Pese a que el Convenio 181 de la OIT establece normas estrictas en la materia y ordena adoptar medidas para garan- tizar la libertad sindical y la negociación colectiva, Colombia aún no ha ratificado ese convenio ni ha tomado medidas eficaces para evitar la violación de la libertad sindical mediante las EST.

La actualidad del sindicalismo en Colombia no es alentadora. Según la Escuela Nacional Sindical (2014), para el mes de diciembre de 2012 estaban sindicalizadas 869,382 personas, menos del $5 \%$ de la población económicamente activa, porcentaje mucho más bajo que el registrado en países con fuerte presencia del neoliberalismo, como Chile, con el $12 \%$ de sindicalización (Soto \& Gaete, 2013). Pese a la baja afiliación, las organizaciones sindicales aún son las asociaciones más representativas y el tipo de movimiento social más controlado por el Estado colombiano y estigmatizado por la ciudadanía. Más de 1,800 sindicalistas han sido asesinados desde 1991; según la CIOSL, el 80 \% de los sindicalistas que mueren violentamente en el mundo son colombianos (Rosado Duque, 2005). Esa realidad, sumada a las actuales condiciones de trabajo, tiende a acentuarse para los jóvenes, generando dificultades para garantizar el crecimiento de los sindicatos y su renovación generacional.

\section{Método}

Para indagar los significados asociados a trabajo y sindicalismo, se conversó con jóvenes bogotanos de clase media, trabajadores de empresas en el sector privado, algunos de ellos vinculados a través de contratos de prestación de servicios y otros de empresas de servicios temporales, con diversos niveles de escolaridad: bachilleres, técnicos y profesionales. Estas aproximaciones permitieron la realización de nueve entrevistas, con cuatro mujeres y cinco hombres, entre los 25 y 30 años con menos de ocho años en el mercado laboral. Al momento de las entrevistas, cinco de ellos estaban vinculados al movimiento sindical, unos trabajaban para la CGT, otros eran afilados a esa organización; los cuatro restantes carecían de vínculos con el sindicalismo. Esta diferencia provocó un análisis que, en algunos aspectos, permite distinguir entre dos perspectivas narrativas según se tenga o no relación con el movimiento sindical. 
La entrevista etnográfica, herramienta empleada como método de recolección de información, es entendida aquí como una conversación a partir de la cual emergen los significados y las formas culturales presentes en el lenguaje, donde se manifiestan sentidos, valores y prejuicios, entre otras formaciones discursivas propias de una época y lugar concretos. En este tipo de entrevista, el investigador se convierte en un provocador de relatos que, antes de intentar conducir la narrativa, debe propiciarla y permitir al narrador reconstruir su historia en sus propios términos, los cuales son subjetivos y a la vez sociales.

Con las entrevistas se indagaron las trayectorias laborales de los jóvenes, buscando centrar la atención sobre la forma como dentro de ellas se construye el trabajo y el sindicalismo. Para el análisis del material recogido, se utilizó la propuesta de análisis de discurso (AD) de Potter y Wetherell (1996), enfocado en la identificación en los relatos, de los repertorios interpretativos (RI) relacionados con el trabajo y el sindicalismo.

Desde esta perspectiva, por discursos se entiende un conjunto de acciones del lenguaje, y a la vez, de estrategias, que forman parte de prácticas sociales en constante cambio. Mediante los discursos se construyen relaciones sociales y se da forma a los mismos sujetos y objetos de conocimiento de los cuales se habla, lo que no quiere decir que estos carezcan de existencia material. Se partió de considerar que a través de las palabras, no solo se describe una realidad, sino que se da forma a la misma, a través de juegos estratégicos del lenguaje dentro de los cuales se encuentran palabras, fórmulas retóricas, gestos, signos, entonaciones, silencios y demás mecanismos de expresión empleados por personas que hacen parte de una misma comunidad lingüística. Podría decirse entonces que en los discursos se traslapan formas de conocimiento, mecanismos de interacción social, relaciones de poder y expresiones de la cultura que habitan una misma época y espacio.

No existe una forma privilegiada de analizar los discursos. La propuesta de análisis por la cual se ha optado, implica elaborar hipótesis que den cuenta de los propósitos y las consecuencias de una deter- minada forma de usar el lenguaje, lo que enfoca el análisis en el discurso y no en la persona que lo emite. El análisis parte de la identificación de repertorios interpretativos, comprendidos aquí como "unidades lingüísticas relativamente vinculadas e internamente consistentes" (Potter \& Wetherell, p. 3), o "elementos esenciales que los hablantes utilizan para construir versiones de las acciones, los procesos cognitivos y otros fenómenos, los cuales se encuentran constituidos por una restringida gama de términos que se repiten, en ocasiones a través de metáforas clave" (Potter \& Wetherell, 1996, p. 3). De esta manera, los RI circulan en el lenguaje cotidiano y los entrevistados los mencionan reiteradamente, configurando versiones mediante las cuales se significa y se construye la realidad. Sintetizando, el repertorio es una forma particular que los hablantes usan para construir los signficados de la cotidianidad.

Desde esta aproximación, el lenguaje adquiere importancia dentro de la vida social en tanto construye y ordena nuestras percepciones y hace que las cosas sucedan, performando la interacción social (Potter \& Wetherell, 1987). Dentro de esta concepción, el lenguaje no solo es reproducido, sino producido en el habla cotidiana, creando las situaciones concretas y la acción misma. Estas interacciones siempre están envueltas en el trabajo interpretativo que realizan sus participantes, los que utilizan el conocimiento que poseen del contexto (Sisto Campos, 2012).

Para la ubicación de los RI, las entrevistas fueron inicialmente transcritas y luego leídas varias veces, primero de manera individual y luego en sesiones de trabajo conjunto, buscando encontrar las unidades lingüísticas que se repetían y los elementos esenciales que los jóvenes utilizaban para construir sus explicaciones. Posteriormente, se elaboraron matrices de análisis donde se ubicaban y discutían los hallazgos de cada entrevista. Finalmente, se hizo una matriz general donde se presentaban los RI emergentes clara y transversalmente en las transcripciones, discutiendo sus características y contenido, y buscando su relación con elementos del contexto social. De esta manera, a través de la identificación de los RI emergentes en las entrevis- 
tas, se intentó describir los significados que tienen el trabajo y el sindicalismo para nueve jóvenes habitantes de Bogotá, teniendo en cuenta para la discusión, el contexto histórico y sociolaboral que se ha descrito.

Algunas de estas entrevistas, particularmente las de jóvenes sindicalizados, fueron posibles gracias a contactos realizados a través de la Confederación General del Trabajo (CGT). Es relevante señalar este hecho, dada la poca proximidad y el temor que se puede observar en muchos jóvenes colombianos frente al movimiento sindical.

\section{Resultados}

El análisis permitió identificar ocho RI, cuatro relacionados con los significados otorgados al trabajo y cuatro al sindicalismo. La construcción del trabajo incluyó repertorios como: el trabajo como medio de progreso, el trabajo como forma de subsistencia y ascenso social, la educación como elemento necesario para conseguir trabajo y ascender, y finalmente: ningún trabajo es indigno. Por su parte asociados al sindicalismo, se encontraron los siguientes repertorios: el sindicalismo es defensivo, el sindicalismo estigmatizado, sindicalismo y contrato muralla y el problema del relevo generacional en los sindicatos.

\section{El trabajo como medio de progreso y ascenso social}

A mí lo que me pasó aquí fue muy bonito, yo siempre veía a los jóvenes cuando estaban estudiando y cuando entraban a una empresa a trabajar, que aprovechaban lo que tenían y estudiaban y estudiaban más, y siempre pedían más y más, y así lo hice cuando empecé a trabajar, use la imaginación para verme cada vez más lejos, y más lejos y más lejos (...) y no quedarme en lo que me inicié, como un auxiliar, y ya con eso voy a vivir y con eso mantengo mi familia, ino! Más bien cada día tener más visión, y pedirle más a la vida, y estudiar, y estudiar, y salir adelante con el trabajo, que uno no tiene que quedarse manos cruzados para que el día de mañana que llegue uno a viejo, se de golpes de pecho, yo no hice nada por esta vida, iqué hice yo? Solo en una oficina, trabajar ahí en una oficina de secretario o auxiliar y no hice nada (...) no, toca es buscar, tener aspiraciones. (Julián)

Por medio de este repertorio se construye el trabajo como una herramienta para el desarrollo económico y social; en él se sostiene la idea según la cual a través del trabajo se puede "progresar", concepto que en Colombia, suele asociarse con un ascenso en la escala social. El repertorio aparece de forma reiterada en las entrevistas de los jóvenes, dándole sentido a un trabajo actual -muchas veces difícil- a partir de cierta promesa de un futuro mejor. De esta manera, se refuerza la noción de que los jóvenes deben "tener aspiraciones" y "tratar siempre de salir adelante". Dentro de una sociedad con fuertes distancias entre las clases sociales, el repertorio permite sostener que se puede eludir, o al menos acortar la distancia, si se trabaja con suficiente empeño y dedicación. Se construye al joven colombiano como alguien perseverante, esforzado, sacrificado y "con aspiraciones", lo que puede verse asociado a efectos subjetivos como la diligencia, la dedicación y cierto disciplinamiento dentro del trabajo.

\section{El trabajo como forma de subsistencia}

Lo que te digo que hacíamos picando plástico, pues bueno era solo picar esas bolsas, pero la verdad muy muy desagradable, nunca pensé que me tocara. Ningún trabajo es deshonra pero en este tiene que andar uno bien sucio, iporque uno tiene que andar bien sucio! y la bodega era, no sé qué medidas tenía, pero era muy grande, y con montañas de bolsas, pero son bolsas de estas de basura, entonces uno está trabajando y veía las ratas caminar. Pues a ese trabajo me llevó un hermano porque yo estaba muy muy mal de plata, y mi hijo tenía un año, entonces él me dijo: pues hay un trabajo, y yo pensé: ide una, lo que sea! entonces me dijo: pero allá hay ratas, y yo iDios mío, no! Bueno, entonces toca estarse agachando, de hecho, yo me lastimé la cintura por eso, porque yo ya me agacho y para pararme es tenaz, de tanto que me agachaba. Entonces uno tiene que escoger el plástico, toca escogerlo para empezar, y agacharse, y corte, y se llenan unas cosas grandísimas que les llaman globos, 
son como lonas grandes, y llénela y llénela y llénele, y lo que pese, imagínate, llenar todo el día. Mi hijo me lo cuidaba mi suegra, pero quedarse ahí es feo y a pesar de eso me tocaba seguir, era simplemente mi forma de subsistencia en ese momento (...). (María)

El repertorio "el trabajo como forma de subsistencia" construye al trabajo como un sacrificio, pero también como un generador de ingresos económicos; usualmente, este repertorio aparece en relación con actividades o trabajos precarios a los que se accede como último recurso de subsistencia dentro de un medio laboral extremadamente difícil. La funcionalidad del repertorio parece responder de manera directa a las condiciones laborales presentes en el actual contexto colombiano. Con él, se trata de dar sentido a trabajos con malas condiciones laborales, a los cuales se accede como último recurso. El repertorio hace evidente y se vincula también, con cierto discurso existente entre la población colombiana, relativo al 'rebusque', término que alude a la capacidad de no quedarse parado, de moverse y 'rebuscarse' la vida. Desde aquí, el colombiano se construye como un sujeto trabajador 'verraco', 'echao pa'lante', que accede a cualquier trabajo si así se necesita. El repertorio puede permitir a los jóvenes sostenerse y luchar dentro de un orden laboral cada vez más complicado e inequitativo con la esperanza de revertir la propia situación de precariedad.

\section{La educación como elemento necesario para conseguir trabajo y ascender}

Nada es gratis en esta vida, si tú quieres algo tienes que luchar por ello, tienes que prepararte para ello, yo he sido, por decirlo así, un poco precoz académicamente, porque me he preparado muchísimo y pienso que los esfuerzos que he hecho los manifiesto en los resultados, y hoy en día me siento totalmente completo en mi parte académica y las expectativas que tenía. Siento que vienen muchas cosas más para mí en el trabajo, porque todavía me estoy preparando (...). (Felipe)

Esto puede estar relacionado con un tema y es la dificultad del joven para acceder a trabajos califi- cados, todo depende de sus niveles de calificación y de formación en sus competencias desde el sector académico. Y eso pues por supuesto, si la persona no tiene grandes dificultades para poder acceder a mejores condiciones laborales. (Pedro)

Este repertorio propone la educación formal y la capacitación, como elementos indispensables a la hora de acceder al trabajo y ascender en él. La educación aparece así construida como un aspecto fundamental, que puede marcar la diferencia entre un buen y un mal trabajo y definir mejores condiciones laborales y ante todo una mejor remuneración para los jóvenes. En las entrevistas, suele aparecer el hecho de que la educación es un privilegio de ciertas élites económicas, que implica un gran esfuerzo para los jóvenes que no pertenecen a ellas. Luchar y prepararse pueden aparecer entonces como sinónimos, prepararse y lograr "mejores oportunidades" son ideas vinculadas también de manera clara. De igual forma, la imposibilidad de esta preparación, implica el cierre y condena a las peores y más difíciles condiciones laborales. En este repertorio la educación parece estar vinculada y supeditada, ante todo, a una noción de acceso al mercado laboral y de mayor competitividad dentro del mismo. El repertorio mantiene y consolida ideas que vinculan formación y competencia laboral, dando prioridad a esta función frente a otras propias de la educación, que no necesariamente buscan dirigirse a asegurar este logro.

\section{Ningún trabajo es indigno}

Ese fue un trabajo feísimo que casi no me gustaba, allá en Ciudad Bolívar es horrible, pero allá dure harto porque en ese tiempo estaba un poco mal, entonces me tocó (...). Personalmente, lo bueno de haber empezado así, es que a mí ya nada me queda grande, no importa lo que tú me pongas a hacer, para mi ningún trabajo es indigno. Entonces yo creo que eso lo hace coger a uno experiencia, y dos que lo vuelve a uno como verraquito, eso le da a uno como verraquera para hacer las cosas, eso es lo que logra uno trabajando desde pequeño. (Juana)

El repertorio "ningún trabajo es indigno" combina la construcción del trabajo como algo valioso, 
con la importancia del esfuerzo en el trabajo, que se ha discutido anteriormente. La noción emergente es que trabajar es valioso por sí mismo y que el trabajo no puede implicar indignidad para quien lo hace independientemente de las condiciones de la labor. Aunque el repertorio construye una valoración hacia la actividad de trabajar y permite encontrar sentido en ella, en contextos como el colombiano puede llegar a sostener y justificar condiciones laborales extremas, sin permitir un cuestionamiento ni la búsqueda de transformación de las mismas. El repertorio permite mantener así la motivación hacia el trabajo incluso bajo condiciones precarias y difíciles.

Antes de continuar hacia los repertorios asociados al sindicalismo, se debe señalar que los repertorios 5, 6, 7 y 8 aparecieron fundamentalmente en jóvenes vinculados con el movimiento sindical; en las entrevistas restantes, el sindicalismo no aparece como tema, lo cual parece confirmar discusiones referentes al poco protagonismo que este tiene entre los jóvenes trabajadores colombianos. Dentro de las entrevistas en las cuales aparece la temática del sindicalismo, surge una narrativa según la cual son las condiciones extremas dentro de sus trabajos las que propician la actividad sindical. Al tiempo, surge con claridad el hecho de que el sindicalismo es una actividad altamente estigmatizada en el país.

\section{El sindicalismo es defensivo}

Nos reunimos con un grupo de trabajadores de la universidad que estábamos preocupados por los derechos de los trabajadores y decidimos fundar el sindicato. Lo formamos con 27 personas de las mínimas requeridas que son 25 (...) esto se dio por que se han desconocido sistemáticamente nuestros derechos por parte de la institución, lo que ya ha conducido a que adelantemos diferentes acciones de tipo judicial y penal, por violación al derecho de asociación, querellas administrativas ante el Ministerio del Trabajo y acciones de tutela en protección a nuestros derechos. (Felipe)

Este repertorio, encontrado en varias de las entrevistas, se relaciona claramente con uno de los discursos que circula de manera más fuerte en relación con el sindicalismo en Colombia. En sus relatos los jóvenes entrevistados asocian frecuentemente el surgimiento de los sindicatos con la necesidad de reivindicar los derechos mínimos consagrados en la ley; explican así el sindicalismo como la última alternativa ante la vulneración de sus derechos y como una de las pocas opciones disponible para luchar contra las actuales condiciones de precariedad laboral. El repertorio permite comprender el surgimiento de una cultura que identifica los mínimos legales con el máximo de justicia laboral posible, perdiendo de vista que la posibilidad de organizarse a través de sindicatos para mejorar la calidad de vida y la distribución de la riqueza producida socialmente, es un derecho fundamental. La popularización de este repertorio permite reforzar la creencia de que, en un país como Colombia, solo puede existir un sindicalismo restringido a la defensa de los derechos económicos de las personas con vínculo de empleo, que carece de proyección social y de legitimidad para ser actor político. A su vez, el repertorio parece tener la función de validar la acción sindical frente a concepciones cada vez más extendidas, que presentan a los sindicalistas como personas inconformes, generadoras de problemas y que "atacan" a las empresas.

\section{El sindicalismo estigmatizado}

Ahora un joven con toda esa realidad sale a buscar trabajo, sale a ubicarse en una empresa, y en la empresa ya lo están estigmatizando porque usualmente usted no se puede vincular a una organización sindical. Hay empresas donde la situación es así, entonces, si una persona se ve en esas condiciones, ve su entorno social y dice: no, yo no me puedo (...) si yo me vinculo a la organización sindical me echan y me dejo de ganar mi salario mínimo, pues ¿tú que vas a hacer?, obviamente tú lo vas a ver de manera muy negativa, y prefieres no vincularte a un tipo de movimiento social. También por desconocimiento, evidentemente, el asunto sindical y la estigmatización se basa también en el desconocimiento. (Diana) 
Pese a que la libre asociación sindical es un derecho fundamental, el discurso que circula en Colombia en relación con el sindicalismo parece evocar el temor de los jóvenes. Así, en el repertorio "el sindicalismo estigmatizado", sindicalizarse equivale a poner en riesgo la continuidad de la relación laboral. La actividad sindical es vista, entonces, como un acto potencialmente peligroso para los jóvenes, que puede conducir a la pérdida del empleo y a la imposibilidad de encontrar uno nuevo. El repertorio se asocia tácitamente con la idea según la cual el sindicalismo amenaza la libertad y la estabilidad empresarial, al tiempo que expone la manera como este ha sido históricamente estigmatizado en Colombia. En el discurso, el estigma persuade a los trabajadores jóvenes a abstenerse de sindicalizarse. La forma como se utiliza el repertorio justifica el mantenerse al margen de la actividad sindical, en tanto esta puede causar problemas en el desarrollo laboral, pero señala también la falta de información y la distorsión del significado del sindicalismo que suele circular socialmente en el país. En este punto, es posible señalar una diferencia importante entre los relatos de quienes han tenido algún contacto con el sindicalismo y quienes se han mantenido al margen: el discurso de los primeros da cuenta de la estigmatización padecida por quienes deciden sindicalizarse, al tiempo que impugna el prejuicio; entre los otros, el silencio frente al tema parecería confirmar la indiferencia o temor existente frente al mismo, y a su vez, el desconocimiento como fuente de temor.

\section{Contrato muralla y sindicalización}

Primero hay un tema externo como del escenario del mercado de trabajo que le dificulta al joven vincularse a las organizaciones sindicales, por ejemplo, y ya lo hemos hablado, es el tema de las formas de contratación. De acuerdo a lo que establece la OIT, la libertad de sindicalización es para todo mundo, y se supondría que independientemente de mi forma de trabajo o de mi vínculo laboral yo podría sindicalizarme sin ningún inconveniente; pero la realidad es otra, la realidad es que a quien se le facilitaría de verdad la posibilidad de sindi- calizarse es a aquellas personas que tienen algún tipo de vínculo laboral que tiene un nivel mucho más amplio de estabilidad. (Pedro)

Los trabajadores que se encuentran con contratos a términos fijos que pueden ser renovados cada tres meses, cada seis meses, cada año, también, pueden afiliarse a una organización sindical, icuál es el problema? pues que la persona que tiene este tipo de contrato se vincula a una organización sindical en el momento en el que se termine el periodo de su contrato, va a ser visto con malos ojos, en función de ser renovados esos contratos. (Pedro)

El repertorio "contrato muralla y sindicalización" aparece con frecuencia en las entrevistas de los jóvenes sindicalizados, haciendo referencia a la relación que para estos existe entre las formas de contratación y la posibilidad de ejercer el derecho de asociación. Dentro del repertorio, la contratación temporal puede pensarse como una muralla frente al sindicalismo, ya que este tipo de contrato impide en la práctica vincularse a un sindicato, y cuando existe tal posibilidad, esta se da junto con el temor de llegar a ser despedido por la organización o de estancarse laboralmente. Esta construcción se relaciona con el repertorio sobre el sindicalismo estigmatizado, discutido anteriormente. Es posible afirmar que la cultura antisindical, promovida por décadas en Colombia a partir de la misma legislación laboral, ha generado un fundado temor a sindicalizarse. En este sentido, el repertorio permite ver la manera como culturalmente se ha sedimentado la restrictiva legislación colombiana; así, pese a identificar la existencia de garantías internacionales, el fragmento señala que las prácticas legales internas tornan ineficaces tales garantías. Nuevamente, aparece una diferencia entre quienes han tenido contacto con el sindicalismo, en tanto tal experiencia les permite cuestionar los contratos precarios y temporales como una forma de menoscabo de los derechos que les asisten como trabajadores, desnaturalizando así las prácticas restrictivas de la libre asociación mediante el discurso. 


\section{El problema del relevo generacional} en los sindicatos

Lo que pasa hoy en día dentro de los sindicatos es que la gente de edad que manejan muchos departamentos, están sesgados en que las cosas se tienen que hacer como ellos digan, y como ellos venían manejándolas desde hace 20 años; entonces, para ellos, ha sido muy difícil que llegue un joven y que traiga otra visión, otra metodología, otra forma de trabajar, para ellos eso es muy duro que les vengan a cambiar su metodología, y es que van a ver las cosas desde otro punto de vista, y es que las cosas no son así. Entonces, yo creo que en esa parte es importante capacitar a todos estas personas de que la juventud viene con ideas frescas y hay que darle la oportunidad, no le cierren las puertas esperando que ellos salgan con una profesión, y que automáticamente tengan 1, 2, 3 años de experiencia. (Julián)

Este repertorio alude a la problemática del relevo generacional en los sindicatos, ya que los jóvenes expresan la dificultad que implica para ellos entrar en la organización sindical. Al tiempo, se construye a sus miembros más antiguos como inflexibles y algo anacrónicos, frente a los sindicalistas jóvenes que vienen con ideas frescas a las que habría que darles una oportunidad. La construcción alude a la perpetuación de los mayores en la dirección de los sindicatos, hecho que se argumenta, genera distanciamientos generacionales y cierta inadaptabilidad de los sindicatos frente a los cambios en el mundo del trabajo. Con esto, los jóvenes parecen justificar el abstenerse de entrar en el mundo sindical. La función de este repertorio parece relacionarse, entonces, con la necesidad de manifestar la inconformidad en relación con el manejo interno del sindicalismo en nuestro país. El repertorio se puede asociar a otro elemento generador de la cultura antisindical en Colombia: el señalamiento de lógicas internas de los propios sindicatos, retroalimentado por el temor que infunden las facultades legales de los empleadores, generando un círculo difícil de romper, en el cual el miedo alimenta la falta de participación y, a su vez, esta propaga el temor a sindicalizarse.

\section{Conclusiones}

A partir de una aproximación al análisis de discurso (AD), en este trabajo se han explorado algunos de los repertorios interpretativos (RI) que sobre trabajo y sindicalismo construyen los jóvenes bogotanos en la actualidad. El marco de la exploración se logró a partir de una contextualización que permite señalar algunas de las condiciones contemporáneas del trabajo para los jóvenes, en lo que se ha denominado los paisajes posfordistas del trabajo. Entre estas, se deben resaltar la inestabilidad, la precariedad, la intensificación y una necesidad de educación y formación, que una vez alcanzada, no siempre se ve compensada con un buen trabajo.

Los RI encontrados en relación con el trabajo en los nueve jóvenes entrevistados, permiten señalar para el contexto colombiano una fuerte construcción del trabajo como forma de subsistencia, lo que hace que ningún trabajo sea indigno, a pesar de las duras condiciones que este pueda llegar a implicar. A la vez, el trabajo se comprende como un medio de progreso y ascenso social, hecho frente al cual la educación aparece como un elemento necesario para conseguir trabajo y ascender. Se propone que estos repertorios aluden a un contexto de grandes diferencias sociales, donde las clases trabajadoras se ven sometidas a condiciones laborales cada vez más precarias, validadas a partir de discursos que permiten a los jóvenes sostenerse y luchar en condiciones usualmente difíciles, con la esperanza de revertir tales condiciones, pero también de romper las brechas sociales que caracterizan la cultura colombiana.

Por su parte, los repertorios sobre sindicalismo fueron encontrados solamente en jóvenes sindicalistas, lo cual parece confirmar discusiones referentes al poco protagonismo que puede llegar a tener la temática sindical dentro de los jóvenes trabajadores no sindicalizados. En este sentido, se puede afirmar, como lo ha señalado Abal (2007) para el contexto argentino, que en Colombia también se observa una gran carencia de experiencias de relación con la instancia sindical en los jóvenes. El contexto colombiano presenta sin embargo la particularidad de que el sindicalismo, más que un significante vacío, 
se ha constituido ante todo en un tema tabú. Esta estigmatización se ha dado como consecuencia de prácticas y discursos presentes por décadas en la historia colombiana, que en muchos casos asimilan el movimiento sindical $-\mathrm{y}$ muchos otros movimientos sociales y políticos- con aparatos ideológicos de los grupos armados. Se propone entonces, que el silencio de algunos jóvenes colombianos sobre el sindicalismo, se puede interpretar como parte y resultado de la polarización interna que ha vivido el país.

En las entrevistas donde aparece la temática del sindicalismo, los jóvenes suelen narrar cómo condiciones extremas dentro de sus trabajos los motivaron a sindicalizarse. Así, emerge con claridad la noción del sindicalismo como una actividad que en muchas ocasiones solo se asume en situaciones límite. En ese sentido, los RI encontrados parecen confirmar un contexto donde el sindicalismo es sancionado, pero también donde la concentración de la dirección de los sindicatos en las figuras más antiguas provoca dificultades para el relevo generacional dentro de los mismos.

Por último, es posible observar diferencias entre los jóvenes sindicalizados y aquellos que no lo son, en la forma en que se hace posible para los primeros cuestionar las condiciones laborales precarias y las situaciones de menoscabo de los derechos que les asisten como trabajadores, desnaturalizando así, mediante el discurso, prácticas restrictivas frente a la libre asociación. Esto no significa que los no sindicalizados se abstengan de cuestionar las condiciones de trabajo, como tampoco implica la imposibilidad para los jóvenes de desarrollar una identidad. Un elemento emergente en los diferentes discursos analizados, tanto de aquellos que se encuentran sindicalizados como de quienes no lo están, es el papel otorgado al trabajo como forjador del carácter, aunque no necesariamente se trate del trabajo-empleo, sino, y con frecuencia, del trabajo por cuenta propia. Se cierra con esto porque es necesario adelantar nuevas investigaciones en las que se puedan explorar las prácticas y los discursos que construyen los jóvenes en el marco establecido por el "emprendimiento" y las formas de trabajo por cuenta propia emergentes en el contexto colombiano, caracterizado por el 'rebusque' y la informalidad.

\section{Referencias}

Abal, P. (2004). Identidades colectivas y dispositivos de control en el marco del empleo asalariado joven. Un estudio de casos en el sector supermercadista. Revista Argentina de Sociología, 2(3), 74-94.

Abal, P. (2007). El destierro de la alteridad. El caso Wal Mart Argentina. Revista Mexicana de Sociología, 69(4), 683-727.

Abal, P. (2011). Estatutos sindicales, la fuente olvidada. El caso de las estructuras sindicales de empleados de comercio. Trabajo y Sociedad, 17, 213-227.

Battistini, O., \& Wilkis, A. (2005). El valor del trabajo en las construcciones identitarias de un grupo de asalariados jóvenes. Cuadernos de Antropología Social, 22, 55-75.

Bourdieu, P. (2002). La 'juventud' no es más que una palabra. En P. Bourdieu, Sociología y Cultura (pp. 163-173). México: Grijalbo.

Caamaño Rojo, E. (2005). Las transformaiones del trabajo, la crisis de la relacion labroral normal y el desarrollo del empleo atípico. Revista de Derecho, 18(1), 25-53.

Dávila León, O. (2002) Biografías y trayectorias juveniles. Ultima Década, 17, 97-116

De la Garza, E. (2003). La flexibilidad del trabajo en América Latina. En E. de la Garza (Coord.), Tratado latinoamericano de sociología del trabajo (pp. 148-178). México: Fondo de Cultura Económica.

De la Garza, E. (2011). Más allá de la fábrica: los desafíos teóricos del trabajo no clásico y la producción inmaterial. Revista Nueva Sociedad, 232, 50-70.

De Oliveira , O., \& Mora Salas, M. (2012). Las vicisitudes de la inclusión laboral en los albores del siglo XXI: trayectorias ocupacionales y desigualdade sociales entre jóvenes. Revista de Trabajo, 8(10), 159-184.

Dubar, C. (2005). A socialização: construção das identidades sociais e profissionais. São Paulo: Livraria Martins Fontes Esditora.

Escuela Nacional Sindical. (2014). Sistema de Información laboral y sindical (Reporte a diciembre de 2013). Medellín, CO: Autor. Recuperado de http:// ens.org.co/apc-aa-files/40785cb6c10f663e3ec6ea7 ea03aaa15/11_SISLAB_2013_2.pdf 
Ermida, O., \& Colotuzzo, N. (2009). Descentralización, tercerización, subcontratación. Montevideo: Organización Internacional del Trabajo.

Frassa, M. J. (2007). Rupturas y continuidades en el mundo del trabajo. Trayectorias laborales y valoraciones subjetivas del trabajo en un estudio de caso. Memoria Académica, 4, 243-266.

Gámez, J. (2011). Emprendimiento en condiciones críticas. Dos estudios de caso en la ciudad de Bogotá. Gestión y Región, 12, 49-66.

Guiamet, J. (2012). "El cliente siempre tiene la razón": procesos de construcción de subjetividad en trabajadores jóvenes de una cadena multinacional de supermercados en la ciudad de Rosario. Trabajo y Sociedad, 19, 361-373.

Guiamet, J. (2014). "Trabajo de paso" y condición juvenil en una cadena multinacional de supermercados en la ciudad de Rosario, Argentina. Desacatos, $45,71-84$.

Hernández, O. (2006). Tendencias tradicionales y emergentes en el derecho laboral en América Latina. En P. Kurczyn (Coord.), Evolución y tendencias recientes del derecho del trabajo y de la seguridad social en América. Memoria del VI Congreso Regional Americano de Derecho del Trabajo y de la Seguridad Social (pp. 287-316). México: UNAM.

Huws, U. (2003). The making of a cybertariat. Virtual work in a real world. Nueva York: Monthly Review Press/The Merlin Press.

Landa, M., \& Marengo, L. (2010). La metabolización de los cuerpos en el capitalismo avanzado. Trabajo y Sociedad, 14(13), 1-10.

Longo, J. (2012). Las fronteras de la precariedad: percepciones y sentidos del trabajo de los jóvenes trabajadores precarios de hipermercados. Trabajo y Sociedad, 19, 375-392.

Margulis, M., \& Urresti, M. (1996). La juventud es más que una palabra. En M. Margulis (Comp.), La juventud es más que una palabra (pp. 13-31). Buenos Aires: Biblos.

Orejuela, J., Bermúdez, R., Urrea, C., \& Delgado, L. (2013). Inserción laboral de jóvenes profesionales: el caso de los psicólogos bonaventurianos. Cali: Editorial Bonaventuriana.

Organización Internacional del Trabajo. (2006). La libertad sindical: recopilación de decisiones y principios del Comité de Libertad Sindical del Consejo de Administración de la OIT (5.a ed.). Ginebra: Autor.

Ostau de Lafont, F. (2012). Estudio de la conducta antisindical en Colombia. Bogotá: Universidad Libre.

Palomino, H. (2002). Los jóvenes y el trabajo: modelos de inserción y rupturas generacionales. Buenos Aires: Crisol Proyectos Sociales. Recuperado de www. crisol.orgg.ar/Juventud14Los_jovenes_y_el_trabajo.doc

Potter, J., \& Wetherell, M. (1987). Discourse and social psycholgy. Beyond attitudes and behaviour. Thousand Oaks, CA: Sage.

Potter, J., \& Wetherell, M. (1996). El análisis de discurso y la identificación de los repertorios intrepretativos. En A. J. Gordo \& J. L. Linaza (Eds.), Psicologías, discursos y poder (pp. 63-78). Madrid: Visor.

Rosado Duque, J. B. (2005). El sindicalismo colombiano: actor social en medio de la guerra y el temor de la libertad. En E. de la Garza, Sindicatos y nuevos movimientos sociales en América Latina (pp. 96 120). Buenos Aires: CLACSO.

Sánchez-Castañeda, A., Reynoso, C., \& Palli, B. (2011). La subcontratación: un fenómeno global. Estudio de Legislación Comparada. México: UNAM.

Sennett, R. (2000). La corrosión del carácter. Las consecuencias personales del trabajo en el nuevo capitalismo. Barcelona: Anagrama.

Sisto Campos, V. (2012). Análisis del discurso y psicología: a veinte años de la revolución discursiva. Revista de Psicología, 21(1), 185-208.

Soto, A., \& Gaete, T. (2013). Tensiones en la construcción identitaria individualizada en el trabajo flexible. Universitas Psychologica, 12(4), 1167-1180.

Souto, S. (2007). Juventud, teoría e historia: la formación de un sujeto social y un objeto de análisis. Historia Actual Online, 13, 171- 192.

Svampa, M. (2009). Identidades astilladas. De la patria metalúrgica al Heavy Metal. En M. Svampa (Ed.), Desde abajo. La transformación de las identidades sociales (pp. 106-136). Buenos Aires: Biblos.

Urrutia, M. (1978). Historia del sindicalismo en Colombia. Bogotá: La Carreta.

Weller, J. (2008). Oportunidades y obstáculos. Las características de la inserción laboral juvenil en economías en expansión. Revista de Trabajo, 4(6), 103-122. 